\title{
Living-cell imaging of transgenic rat anterior pituitary cells in primary culture reveals novel characteristics of folliculo-stellate cells
}

\author{
Kotaro Horiguchi, Motoshi Kikuchi, Kenji Kusumoto, Ken Fujiwara, Tom Kouki, \\ Kotaro Kawanishi and Takashi Yashiro \\ Division of Histology and Cell Biology, Department of Anatomy, Jichi Medical University School of Medicine, 3311-1 Yakushiji, Shimotsuke, \\ Tochigi 329-0498, Japan \\ (Correspondence should be addressed to K Horiguchi; Email: kota@jichi.ac.jp; T Yashiro; Email: tyashiro@jichi.ac.jp)
}

\begin{abstract}
Folliculo-stellate (FS) cells in the anterior pituitary gland appear to possess multifunctional properties. Recently, the development of transgenic rats (S100b-green fluorescent protein (GFP) rats) that express GFP specifically in FS cells in the anterior pituitary gland has allowed us to distinguish and observe living FS cells in other kinds of pituitary cells. We used S100b-GFP rats to investigate the topographic affinity of FS cells for other pituitary cells. We observed living FS cells in enzymatically dispersed anterior pituitary cells of S100b-GFP rats under a fluorescent microscope, and noted that FS cells markedly extended and contracted cytoplasmic processes and formed interconnections with neighboring FS cells. In addition, FS cells adhered to small clusters of GFPnegative cells, which were primarily hormone-producing cells, and these clusters further aggregated during the course
\end{abstract}

of cytoplasmic contraction. In the presence of laminin, fibronectin, and varying types of collagen, FS cells showed marked changes in shape and specific proliferative activity; however, GFP-negative cells did not. On reverse transcriptionPCR analysis and immunohistochemistry, FS cells were shown to express integrin subunits, which are the cell surface receptors for extracellular matrix (ECM). In the anterior pituitary gland, FS cells and the various types of hormoneproducing cells generate a unique topography in the presence of basement membrane components and interstitial collagens. The novel characteristics of FS cells observed in the present study suggest that in the anterior pituitary gland, FS cells play important roles in determining and/or maintaining local cellular arrangement in the presence of ECM components. Journal of Endocrinology (2010) 204, 115-123

\section{Introduction}

The anterior pituitary gland is composed of five types of hormone-producing cells and the folliculo-stellate cells (FS cells), which do not produce the classical anterior pituitary hormones. In vivo, these cells are surrounded by different types of extracellular matrices (ECMs), which provide the mechanical integrity, rigidity, and elasticity that are essential for these cells to perform their respective roles (Gon et al. 1987, Soji \& Herbert 1989, Paez-Pereda et al. 2005). It has been shown that the lobular structures that are surrounded by ECM are responsible for organizing the functional unit in the anterior pituitary gland (Gon et al. 1987, Soji \& Herbert 1989, Inoue et al. 1999, Shirasawa et al. 2004). Knowledge of the topographic features of FS cells is essential for understanding this lobular structure, the location of FS cells in the core of the lobular structure, and the characteristic enveloping of hormone-producing cells by their cytoplasmic processes, the tips of which sometimes attach to the ECM (Soji \& Herbert 1989, Inoue et al. 1999, Shirasawa et al. 2004).
In addition, the anterior pituitary cells construct a unique topography by means of homophilic and heterophilic affinities between cell types (Noda et al. 2001), and by differential affinities to the ECM types (Denduchis et al. 1994, Diaz et al. 2002). The functions of hormone-producing cells are mainly regulated by endocrine, autocrine, and paracrine signaling. In addition to this humoral regulation, their functions are believed to be modified by juxtacrine signaling, by which cells receive components of the plasma membrane from adjacent cells as signals (Vankelecom \& Denef 1997), and matricrine signaling, by which cells receive components of the ECM as a signal (Paez-Pereda et al. 2005).

Recently, Itakura et al. (2007) succeeded in producing transgenic rats (S100b-green fluorescent protein (GFP) rats) that express GFP specifically in FS cells in the anterior pituitary gland. The existence of S100b-GFP rats allows us to distinguish living FS cells and to separate them from the hormone-producing cells. Cell-to-cell interactions between FS cells and between FS cells and hormone-producing cells have been studied and described by several research groups (Rinehart \& Farquhar 1953, Vankelecom \& Denef 1997, 
John et al. 2004). However, by utilizing S100b-GFP rats, we are now able to develop new approaches to investigate these interactions.

In a recent study using these transgenic rats, we found that FS cells of the S100b-GFP rats encircled hormone-producing cells with their cytoplasmic processes to form cell clusters (i.e. FS cells aggregated homophilically) both in vivo and in vitro (Horiguchi et al. 2008). It is likely that these histological features provide a suitable environment for cellto-cell communication in the anterior pituitary gland. However, there is a limited understanding of the means by which FS cells reconstruct these histological features in primary culture, and the mechanisms underlying the interaction between FS cells and ECM. In the present study, we used living FS cells of the S100b-GFP rats to investigate both the behavior of FS cells during cluster formation and the morphological and functional responses of FS cells to the different ECM components in primary culture. We believe that the use of the S100b-GFP rats, in conjunction with living-cell imaging, may be the only method available to reveal these salient characteristics of FS cells in the anterior pituitary gland.

\section{Materials and Methods}

\section{Animals}

Transgenic S100b-GFP rats that express GFP under the control of the promoter of the $S 100 \beta$ protein gene - a marker of FS cells - were donated by Prof. K Inoue of Saitama University and were bred in our laboratory (Itakura et al. 2007). Eight- to $10-$ week-old male rats weighing 250-300 g were given access to food and water ad libitum, and were housed under conditions of $12 \mathrm{~h}$ light: $12 \mathrm{~h}$ darkness. Rats were killed by exsanguination from the right atrium under deep Nembutal anesthesia, and were then perfused with $\mathrm{Ca}^{2+}$ - and $\mathrm{Mg}^{2+}$-free Hanks' solution for primary culture or with $4 \%$ paraformaldehyde in $50 \mathrm{mM}$ cacodylate buffer $(\mathrm{pH} 7 \cdot 4)$ for immunohistochemistry. All animals were treated in accordance with the Guidelines for Animal Experimentation of Jichi Medical University. These guidelines are based on the NIH Guidelines for the Care and Use of Laboratory Animals.

\section{Cell culture}

Anterior pituitary cells of S100b-GFP male rats were dispersed as described previously (Horiguchi et al. 2008). Dispersed cells were plated onto eight-well glass chamber slides $\left(1 \mathrm{~cm}^{2} /\right.$ well; Nalge Nunc International, Rochester, NY, USA) with or without a coating of ECM substrates $3 \mu \mathrm{g} / \mathrm{cm}^{2}$ of collagen type I, type III, or type IV (Nitta Gelatin, Osaka, Japan), or $10 \mu \mathrm{g} / \mathrm{cm}^{2}$ of laminin (Millipore, Bedford, MA, USA) - at a density of $1 \times 10^{5}$ cells $/ \mathrm{cm}^{2}$ in
$400 \mu \mathrm{l}$ of Medium 199 with Earle's salts (Invitrogen) supplemented with 10\% fetal bovine serum (Sigma-Aldrich Corp.), $0.5 \mathrm{U} / \mathrm{ml}$ penicillin, and $0.5 \mu \mathrm{g} / \mathrm{ml}$ streptomycin (Invitrogen). Cells were also plated onto a fibronectincoated dish $\left(9 \mathrm{~cm}^{2} /\right.$ well; IWAKI, Tokyo, Japan) under the same conditions described above. Cells were then cultured for $72 \mathrm{~h}$ at $37^{\circ} \mathrm{C}$ in a humidified atmosphere of $5 \% \mathrm{CO}_{2}$ and $95 \%$ air.

\section{Time-lapse observation of primary culture}

The cells were cultured in a $\mathrm{CO}_{2}$ gas culture chamber (Sankei Corp., Tokyo, Japan) with a thermostat (Kokensha Engineering Corp., Tokyo, Japan) on a fluorescence-inverted microscope (IX71; Olympus Corp., Tokyo, Japan). Culture conditions were the same as described above. We time-lapse recorded the cells by using a digital camera (ORCA-ER; Hamamatsu Photonics, Shizuoka, Japan) and MetaMorph software (Molecular Devices Corp., Downingtown, PA, USA). Each observation was performed in triplicate.

\section{Fluorescent cytochemistry of actin filaments}

To observe cellular localization of actin filaments, cells were fixed with $4 \%$ paraformaldehyde in $25 \mathrm{mM}$ phosphate buffer $(\mathrm{pH} \mathrm{7.4)}$ for $20 \mathrm{~min}$, and were permeabilized with $0 \cdot 4 \%$ Triton X-100 in PBS for $5 \mathrm{~min}$ at room temperature. Fixed cells were incubated in PBS containing $2 \%$ normal goat serum for $20 \mathrm{~min}$ at $30^{\circ} \mathrm{C}$, incubated with $0.1 \mu \mathrm{M}$ rhodamine-phalloidin (Cytoskeleton Inc., Denver, CO, USA) for $30 \mathrm{~min}$ at room temperature, and washed with PBS. Cells were scanned using a confocal laser microscope (FV1000; Olympus).

\section{Immunohistochemistry}

Pituitary glands were carefully excised and fixed overnight in $4 \%$ paraformaldehyde in $50 \mathrm{mM}$ cacodylate buffer $(\mathrm{pH}$ $7 \cdot 4)$ at $4{ }^{\circ} \mathrm{C}$. Tissues were then immersed in cacodylate buffer ( $\mathrm{pH} 7 \cdot 2$ ) containing $30 \%$ sucrose for 2 days at $4{ }^{\circ} \mathrm{C}$, embedded in Tissue-Tek OCT compound (Sakura Finetechnical, Tokyo, Japan), and frozen rapidly. Frozen frontal sections of $8 \mu \mathrm{m}$ thickness were obtained using a cryostat (CM3000; Leica Microsystems, Wetzlar, Germany) and were mounted on slide glasses. Sections were incubated in PBS containing 2\% normal goat serum for $20 \mathrm{~min}$ at $30{ }^{\circ} \mathrm{C}$, and were then incubated overnight with mouse antirat integrin $\beta 1$ monoclonal antibody $(12.5 \mathrm{ng} / \mathrm{ml} ; \mathrm{BD}$ Biosciences, Erembodegem, Belgium) at room temperature. After washing with PBS, sections were incubated in PBS with Alexa Fluor 568-conjugated goat anti-mouse IgG (Invitrogen) diluted to 1:200 and were washed with PBS again. Sections were scanned using a confocal laser microscope. 


\section{Proliferation assay}

To visualize the proliferative activities of cells, the nucleotide analog 5-bromo-2'-deoxyuridine (BrdU, Sigma-Aldrich Corp.) was added to primary culture for $24 \mathrm{~h}$ at a concentration of $3 \mu \mathrm{g} / \mathrm{ml}$. Cells were fixed in $4 \%$ paraformaldehyde in $25 \mathrm{mM}$ phosphate buffer $(\mathrm{pH} 7 \cdot 4)$ for $20 \mathrm{~min}$ at
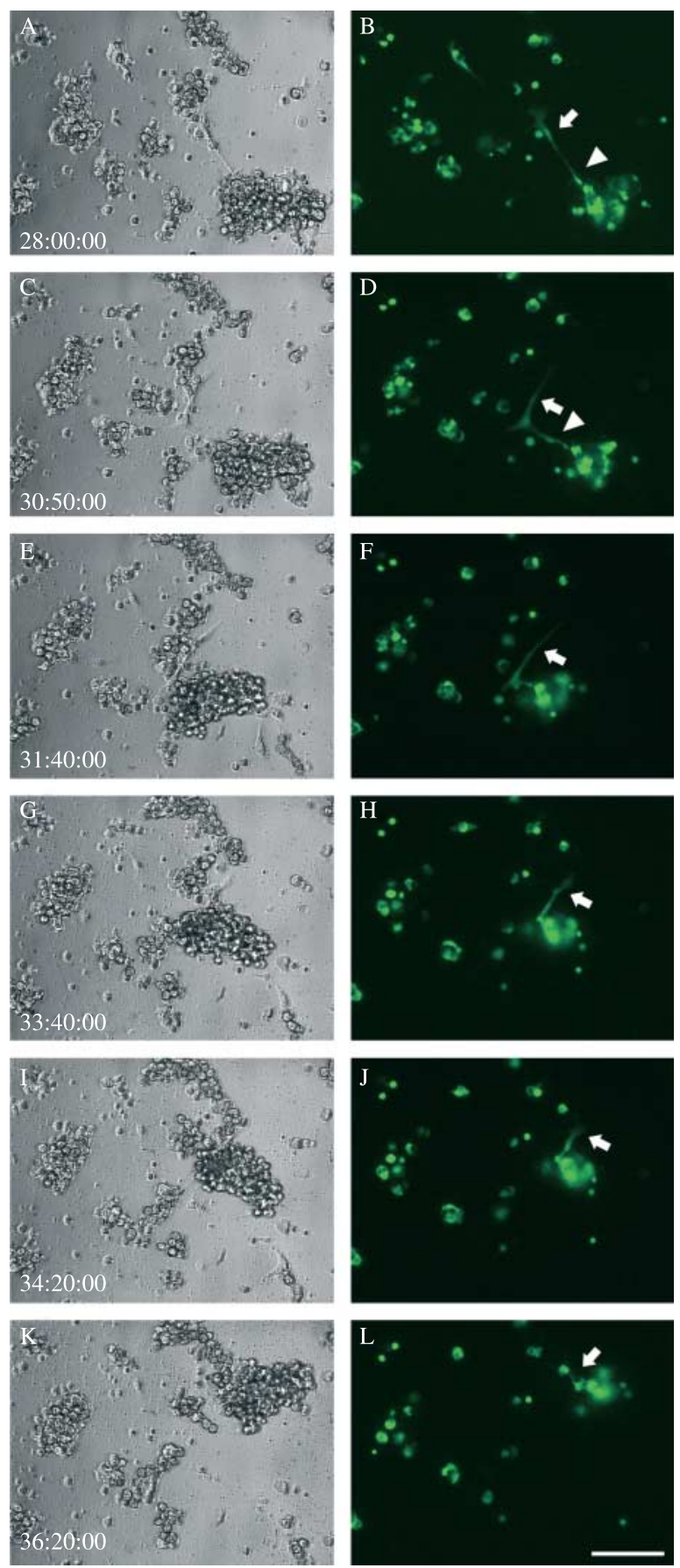

room temperature, and were then treated with $4 \mathrm{M} \mathrm{HCl}$ in PBS for $10 \mathrm{~min}$. Cells were incubated in PBS containing 2\% normal goat serum for $1 \mathrm{~h}$ at $30^{\circ} \mathrm{C}$, and were then incubated with anti-rat BrdU mouse monoclonal antibody $(1.5 \mu \mathrm{g} / \mathrm{ml}$, Sigma-Aldrich Corp.) for $90 \mathrm{~min}$ at $30^{\circ} \mathrm{C}$. After washing with PBS, cells were incubated in PBS with Alexa Fluor 568-conjugated goat anti-mouse IgG (Invitrogen) diluted to 1:200. The absence of an observable nonspecific reaction was confirmed using normal mouse serum. Thirty random fields were imaged per well using a confocal laser microscope with a 60-fold objective lens. The percentage of immunoreactive cells was calculated by counting at least 1500 cells per well. The observations were done three times for each experimental group.

\section{Reverse transcription-PCR analysis of integrin subunit gene expression}

Total RNA fractions were prepared with Trizol reagent (Invitrogen) from anterior pituitary glands, anterior pituitary cell primary culture, and the GFP-positive cell fraction of S100b-GFP male rats. They were then sorted by a MoFlo XDP (Beckman Coulter, Inc., Fullerton, CA, USA) and were incubated with RNase-free DNase I $(1 \mathrm{U} /$ tube; Promega Corp). As positive controls of integrin subunit gene expression, total RNA fractions were also prepared from the adrenal gland (Otis et al. 2007) and whole fetus of S100b-GFP male rats. After inactivation of DNase I by heating for $10 \mathrm{~min}$ at $65^{\circ} \mathrm{C}$, cDNA was synthesized using a Superscript III reverse transcription kit with oligo- $(\mathrm{dT})_{20}$ primer (Invitrogen). For PCR, $1 \mu \mathrm{l}$ of the reverse transcription (RT) reaction product was added to $9 \mu$ of PCR buffer containing $1 \mu \mathrm{l}$ deoxy-NTPs $(2 \mathrm{mM}), 0 \cdot 1 \mu \mathrm{l}$ KOD Dash DNA polymerase $(2.5 \mathrm{U} / \mu \mathrm{l}$; TOYOBO, Osaka, Japan), and $0 \cdot 1 \mu \mathrm{l}$ of each oligonucleotide primer listed below $(10 \mu \mathrm{M})$.

The primer pairs used and putative product lengths were as follows: integrin $\beta 1$ (GeneBank accession no. NM_017022), forward: 5'-CTTACTCAGGCGGAGTTTGC-3', reverse: 5'-TCACAATGGCACACAGGTTT-3' (598 bp); integrin a1 (NM_030994), forward: 5'-ACTGGAACGGAACTGTGGTC- $3^{\prime}$, reverse: $5^{\prime}$-CCTAATTGGTTCCAGGCTCA-3'

Figure 1 Time-lapse images of S100b-GFP male rat anterior pituitary cells in primary culture. Cells were time-lapse recorded at 2-min intervals under a fluorescence-inverted microscope from 28 to $37 \mathrm{~h}$ after the cells were plated. The cytoplasmic processes of FS cells (arrowheads) formed interconnections (arrows) (A and B). These FS cells moved closer to each other by contracting their cytoplasmic processes. Finally, they gathered nearby small clusters of GFP-negative cells, thereby forming a large cluster ( $\mathrm{K}$ and $\mathrm{L}$ ). $(A, C, E, G, I$, and $K)$ Phase-contrast images of single frames from time-lapse movie 1. (B, D, F, H, J, and L) Fluorescence images corresponding to A, C, E, G, I, and $\mathrm{K}$ from time-lapse movie 2 respectively. The time elapsed from plating of cells is shown in the lower left corner as h:min:s. Scale bar, $100 \mu \mathrm{m}$. 

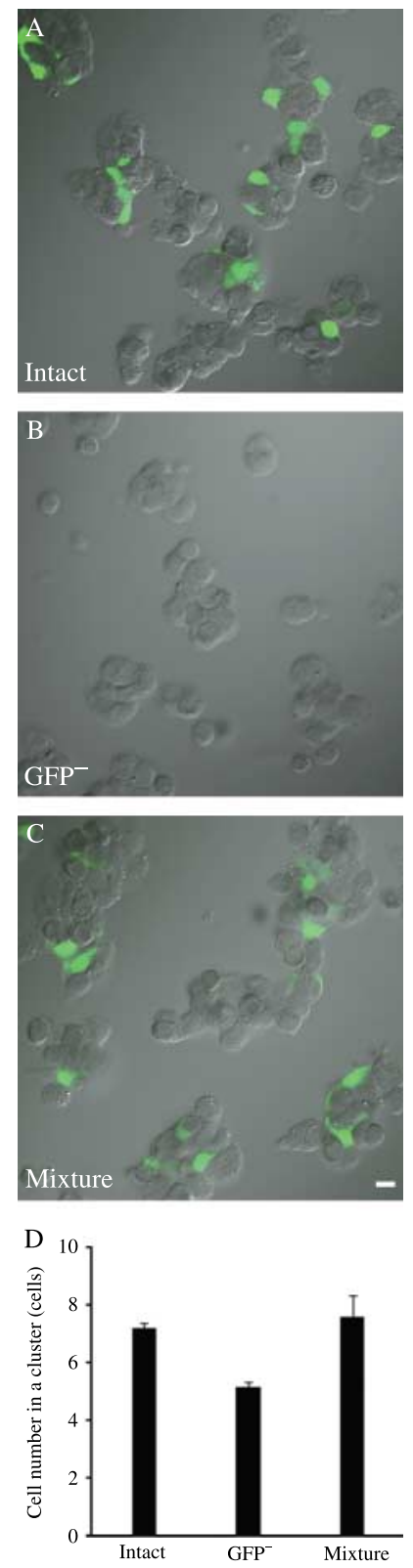

Figure 2 Number of cells in clusters with or without FS cells. (A, B, and C) GFP images superimposed on phase-contrast images using a confocal laser microscope (A; Intact, B; GFP-negative, and C; Mixture). (D) The average numbers of cells in a cluster. The cell number was obtained by counting at least 1500 cells per well in 30 random fields. Data are expressed as mean \pm s.E.M. $(n=3)$. The significance of the differences between intact and GFP-negative cultures and between mixture and GFP-negative cultures was determined by the Bonferroni test $(P<0 \cdot 05)$. Scale bar, $10 \mu \mathrm{m}$.

(437 bp); integrin $\alpha 2$ (XM_345156), forward: 5'-ATATGCCAACGACCCAAGAG-3', reverse: 5'-CACTGCACCTAGCATCAGGA-3' (553 bp); integrin a3 (NM_00110 8292), forward: 5'-GTCTGGAAACCTTCTCAACCC-3', reverse: 5'-CAACCACAGCTCAATCTCAGC-3' (436 bp)
(Yashpal et al. 2005); integrin a6 (XM_215984), forward: 5'_CCCAAGGAGATTAGCAATGGC-3', reverse: 5'-CAGTCTTTGAGGGAAACACCG-3' (452 bp) (Yashpal et al. 2005); integrin $\alpha 10$ (NM_001107699), forward: 5'-TGTGGAAGCTTGGCTTCTTT-3', reverse: 5'-GGCAGGAAGGTGAGAGAGTG-3' (494 bp); integrin $\alpha 11$ (NM_001108156), forward: 5'-AGAAGCCCGTGCAGAGAATA-3', reverse: 5'-CCCTGTTGGTGAACTGGTCT-3' (420 bp); GH (NM_001034848), forward: 5'-CAAGAGGCTGGTGCTTTACC-3', reverse: 5'-TGAGGATCTGCCCAATACGG-3' (427 bp); S100 $\beta$ protein (BC_087026), forward: 5'-ATAGCACCTCCGTTGGACAG-3', reverse: 5'-CATCTCAGTGGCCCTTCATT-3' (527 bp); and glyceraldehyde 3-phosphate dehydrogenase (Gapdh; M_17701), forward: 5'-CCATCACCATCTTCCAGGAG-3', reverse: 5'-TTCAGCTCTGGGATGACCTT-3' (457 bp). Samples were subjected for $2 \mathrm{~min}$ at $94^{\circ} \mathrm{C}, 25(\mathrm{GH}, \mathrm{S} 100 \beta$ protein, and $\mathrm{GAPDH})$ or 30 (integrin- $\beta 1,-\alpha 1,-\alpha 2,-\alpha 3,-\alpha 6,-\alpha 10$, and $-\alpha 11$ ) cycles of $30 \mathrm{~s}$ at $94^{\circ} \mathrm{C}, 2 \mathrm{~s}$ at $58^{\circ} \mathrm{C}, 30 \mathrm{~s}$ at $74{ }^{\circ} \mathrm{C}$, and then for an additional $7 \mathrm{~min}$ at $72{ }^{\circ} \mathrm{C}$ in a GeneAmp PCR System 9700
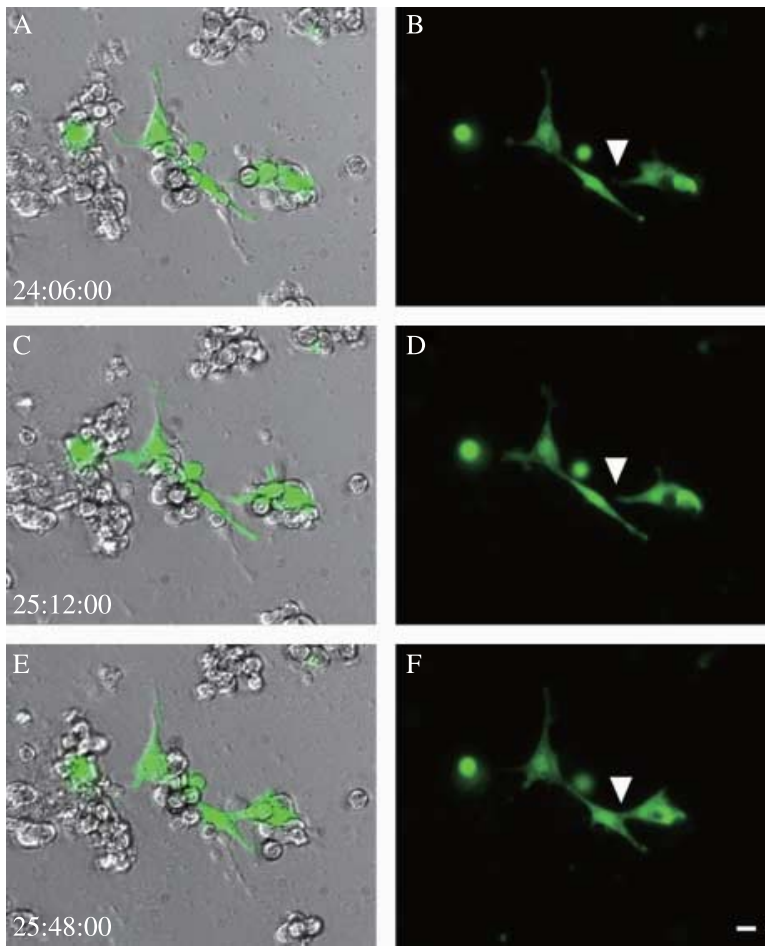

Figure 3 Time-lapse images of FS cell adhesion. Cells were timelapse recorded at 3-min intervals under a fluorescence-inverted microscope from 24 to $26 \mathrm{~h}$ after the cells were plated. FS cells extended their cytoplasmic processes, which resulted in adherence (arrowheads). FS cells can be distinguished from fibroblasts by the presence of GFP in the former. (A, C, and E) Single frames from a time-lapse movie. (B, D, and F) Fluorescence images corresponding to $A, C$, and $E$ respectively. The time elapsed from plating of cells is shown in the lower left corner as h:min:s. Scale bar, $10 \mu \mathrm{m}$. 

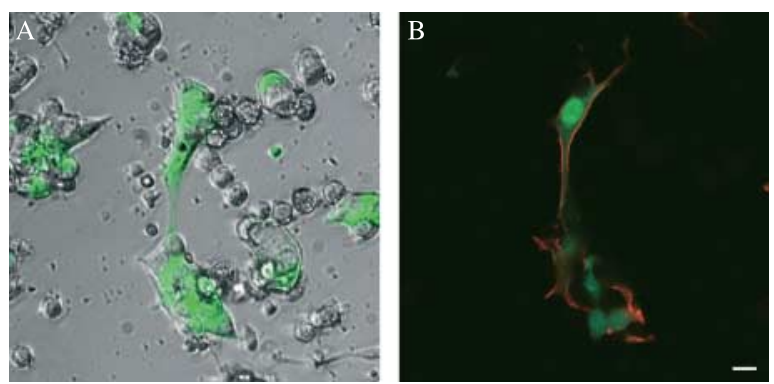

Figure 4 Observation of actin filaments in FS cells. (A) GFP image superimposed on a phase-contrast image of primary culture.

(B) Cells were fixed and actin filaments were stained with rhodamine-phalloidin fluorescent cytochemistry (green, FS cells and red, actin filaments). Scale bar, $10 \mu \mathrm{m}$.

(Applied Biosystems, Foster City, CA, USA). The amplified products were analyzed on $1 \cdot 5 \%$ agarose gels and were visualized by ethidium bromide staining. Negative controls were subjected to RT-PCR omitting RT, cDNA, or KOD Dash DNA polymerase, and they showed no reaction bands.

\section{Statistical analyses}

The data are presented as the mean \pm s.E.M. for at least three rats in each group. The significance of differences between control and test values was determined by Dunnett's test and the two-tailed multiple $t$-test with Bonferroni correction (three comparisons in three groups). Differences were considered significant when $P$ was $<0 \cdot 05$.

\section{Results}

\section{Living-cell imaging of FS cells in primary culture}

We observed the behavior of living FS cells in primary culture of S100b-GFP male rat anterior pituitary cells. The cells were cultured in a $\mathrm{CO}_{2}$ gas culture chamber on a fluorescenceinverted microscope and were photographed every 2 or $3 \mathrm{~min}$ for a period of $72 \mathrm{~h}$. We observed that FS cells were remarkably motile (Fig. 1, Supplementary movies 1 and 2, see section on supplementary data given at the end of this article) as compared to GFP-negative cells, which were primarily hormone-producing cells. At $28 \mathrm{~h}$ of primary culture, cytoplasmic processes of some FS cells had extended $\sim 50 \mu \mathrm{m}$, and FS cells were interconnected by these processes (Fig. 1B). Thereafter, the FS cells contracted their cytoplasmic processes, aggregated (Fig. 1D), and gathered adjacent GFPnegative cells into a cluster. Between 31 and $37 \mathrm{~h}$ of culture, FS cells (Fig. 1F, H, and J) continued the extension and contraction of their cytoplasmic processes, thereby assembling ever-larger clusters. FS cells moved at an average rate of $6 \mu \mathrm{m} / \mathrm{min}$ during a 9-h observation. During the course of observation, the cytoplasmic processes of some FS cells encircled GFP-negative cells (Fig. 1L). After $72 \mathrm{~h}$, the morphology of cells did not differ from that observed in conventional primary culture. Next, we counted the number of cells in clusters with or without FS cells. Dispersed cells were separated into GFP-positive and GFP-negative cells by a cell sorter (MoFlo XDP: Beckman Coulter, Inc). GFP-positive and GFP-negative cells amounted to 5 and $95 \%$ of dispersed cells respectively. The percentage of GFPpositive cells among all dispersed cells was nearly equal to that noted in a previous report (Itakura et al. 2007). Unsorted cells (Fig. 2A), GFP-negative cells (Fig. 2B), and a mixture of 5\% GFP-positive/95\% GFP-negative cells (Fig. 2C) were cultured at a density of $1 \times 10^{5}$ cells $/ \mathrm{cm}^{2}$ for $72 \mathrm{~h}$ on the uncoated surface of eight-well glass chamber slides. The number of cells among the GFP-negative fraction cluster was lower than that among the unsorted cells (Fig. 2D). When GFP-positive cells were added to GFP-negative cells, the number of cells in a cluster was similar to that observed among the unsorted cells (Fig. 2D).

Figure 3 shows the cytoplasmic process of an FS cell attaching to another FS cell at $\sim 24 \mathrm{~h}$ of primary culture. This extension of the cytoplasmic process from one FS cell to another was quite precise (Fig. 3B, D, and F).

\section{Actin arrangement in FS cells}

We observed the actin arrangement of motile FS cells. FS cells were photographed during the course of cell binding under a fluorescence-inverted microscope at $\sim 24 \mathrm{~h}$ after they were plated (Fig. 4A). They were then fixed with $4 \%$ paraformaldehyde and were subjected to fluorescent cytochemistry for actin. Actin filaments were detected along the elongated cytoplasmic processes (Fig. 4B).

\section{Morphological changes of FS cells on ECM}

We observed the behavior of FS cells in primary culture on various ECM-coated surfaces. As shown in Fig. 5, many FS cells, with distinct morphological changes, were present on type III collagen after $72 \mathrm{~h}$ of culture; GFP-negative cells
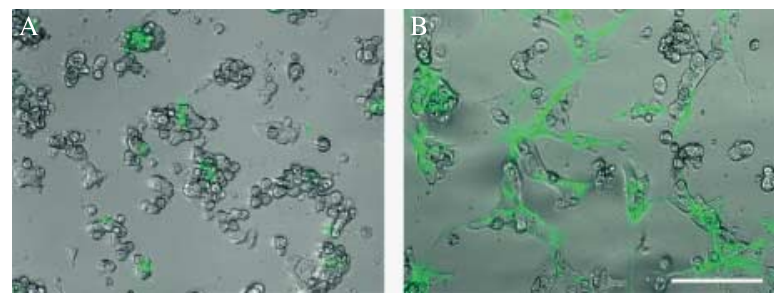

Figure 5 Morphological changes in FS cells on ECM-coated surface in primary culture. FS cells cultured on a surface coated with collagen type III (B) had more cytoplasmic processes and more interconnections with adjacent FS cells than did FS cells cultured on an uncoated surface (A). (A) GFP image of FS cells on an uncoated glass surface. (B) GFP image of FS cells on a surface coated with collagen type III superimposed on a phase-contrast image after $72 \mathrm{~h}$ of incubation in primary culture. Scale bar, $100 \mu \mathrm{m}$. 
retained their round shape. FS cells had flattened and markedly extended their cytoplasmic processes. Furthermore, the cytoplasmic processes of a large number of FS cells had interconnected. Similar morphological changes in FS cells were observed on the other ECM surfaces, i.e. collagen type I, collagen type IV, laminin, and fibronectin (data not shown). However, a small number of FS cells retained their round shape, even on ECM.
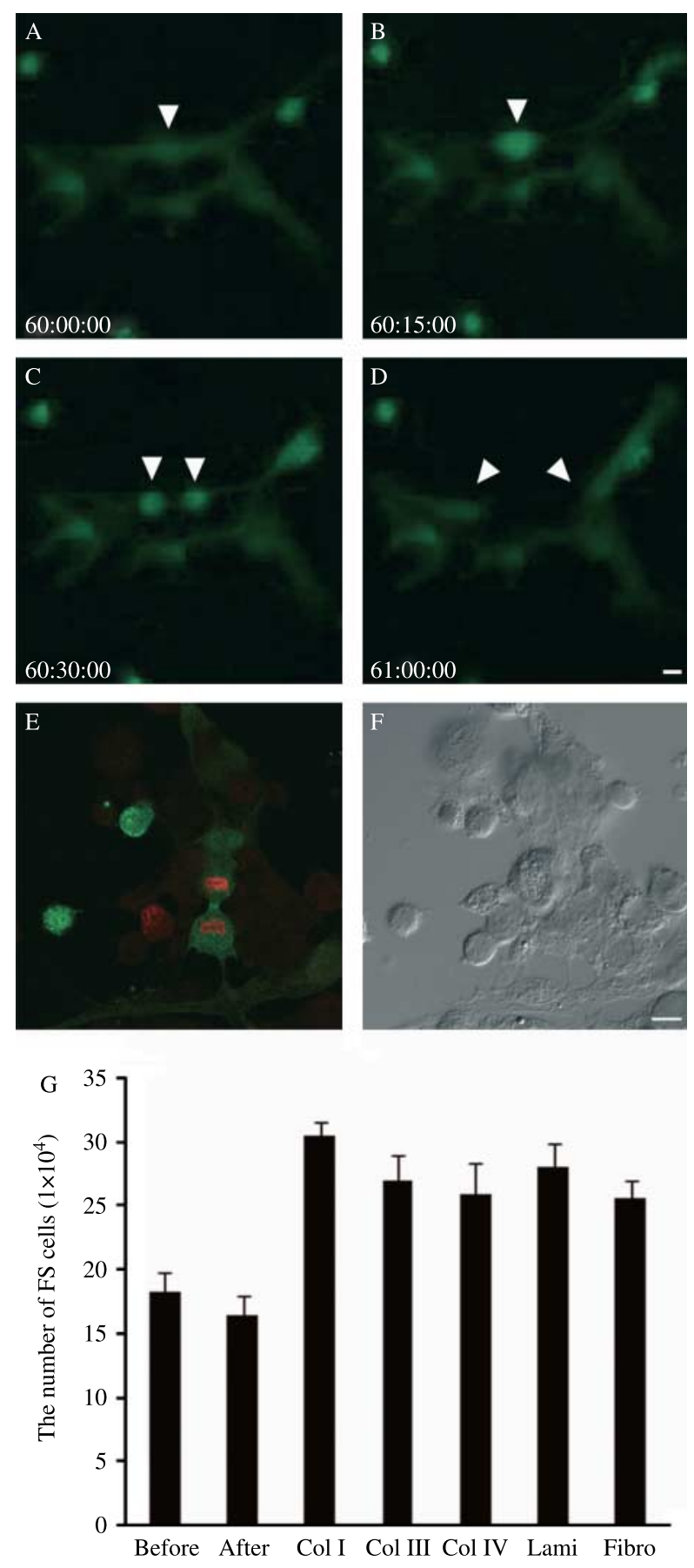

\section{Proliferation of FS cells on ECM}

In primary culture on ECM-coated surfaces, proliferation of FS cells was observed frequently from 48 to $72 \mathrm{~h}$ after the cells were plated. Figure 6A-D and Supplementary movie 3, see section on supplementary data given at the end of this article show the division of an FS cell over a period of $1 \mathrm{~h}$. Observation of BrdU incorporation revealed that only FS cells with cytoplasmic processes showed proliferative activity; round FS cells did not show proliferative activity (Fig. 6E and F). The percentage of BrdU-positive cells among all FS cells was much higher on the type I collagen-coated surface $(22 \cdot 6 \pm 1 \cdot 8 \%$, mean \pm s.E.M., $n=3)$ than on the uncoated surface $(0 \cdot 1 \pm 0 \cdot 1 \%$, mean \pm s.E.M., $n=3)$. Next, we counted the number of FS cells before and after primary culture. The number of FS cells did not differ significantly before and after culture for $72 \mathrm{~h}$ on uncoated glass (Fig. 6G). In contrast, the number of FS cells increased by more than $50 \%$ on all the examined ECM-coated surfaces (Fig. 6G). These differences in the number of FS cells on uncoated and ECM-coated surfaces were statistically significant $(P<0 \cdot 01$, Dunnett's test).

\section{Expression of integrin subunit genes in FS cells}

We examined the expression of integrin subunit genes in FS cells by RT-PCR. Integrin- $\beta 1,-\alpha 1,-\alpha 3$, and $-\alpha 6$ were detected in anterior pituitary cells both in vivo and in vitro; integrin- $\alpha 2,-\alpha 10$, and $-\alpha 11$ were not detected (Fig. 7A). Analysis of GFP-positive and GFP-negative fractions in a cell sorter resulted in identical results, with the exception of $\mathrm{GH}$ and $S 100 \beta$ protein gene, which were not detected in the fractions of GFP-positive and GFP-negative cells respectively (Fig. 7A). Furthermore, immunohistochemical techniques revealed that integrin $\beta 1$ was expressed in GFP-positive and GFP-negative cells (Fig. 7B).

Figure 6 Proliferation of FS cells on collagen type III in primary culture. Cells in culture were time-lapse recorded at 3-min intervals under a fluorescence-inverted microscope from 60 to $61 \mathrm{~h}$ after the cells were plated. During a $1-\mathrm{h}$ period, an FS cell (A, arrowhead) divided on a surface coated with collagen type III in primary culture (A-D). (A-D) Single frames from time-lapse movie 3. (E) Confocal image of BrdU incorporation (green, FS cells and red, BrdU). (F) Phase-contrast image of the same field shown in E. (G) Number of FS cells before and after primary culture on an uncoated glass chamber (before and after), and after primary culture on glass chambers coated with collagen type I (Col I), collagen type III (Col III), collagen type IV (Col IV), laminin (Lami), and fibronectin (Fibro). Cells were retrieved by incubation in $0.3 \%$ EDTA and were then counted with a hemocytometer. The time elapsed from plating of cells is shown as h:min:s in the lower left corner of panels A, B, C, and D. Scale bars, $10 \mu \mathrm{m}$. Data are expressed as mean \pm S.E.M. $(n=5)$. Differences in the numbers of FS cells on uncoated and ECM-coated surfaces were statistically significant $(P<0 \cdot 01$, Dunnett's test). 


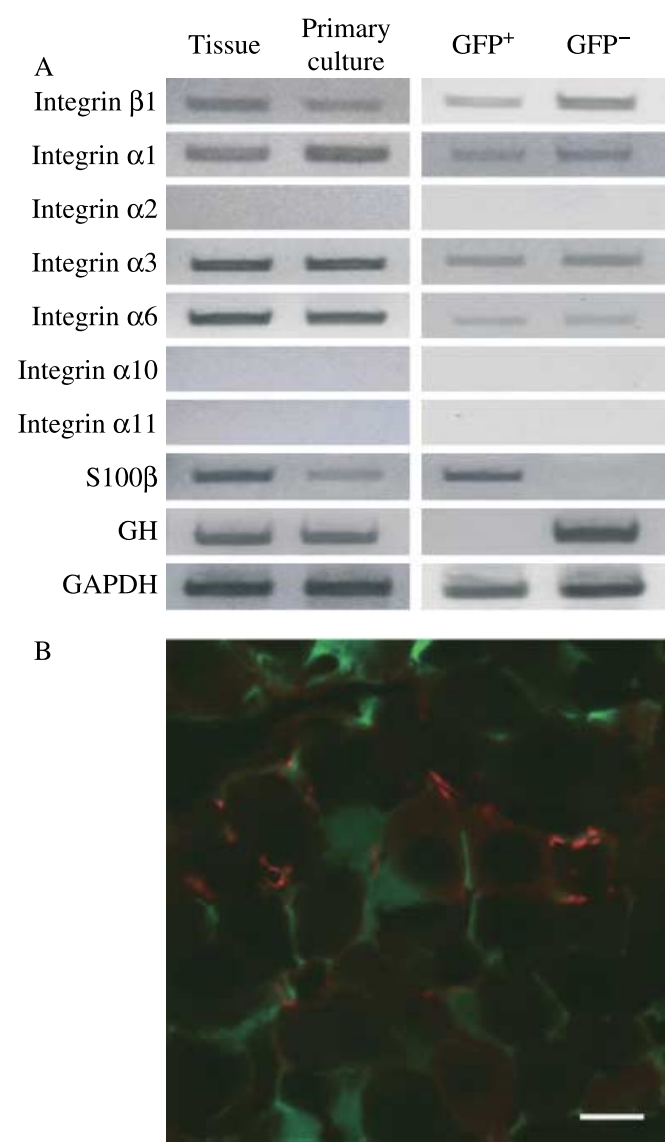

Figure 7 Expression of integrin subunit genes in FS cells. (A) Total mRNA fractions extracted from anterior pituitary tissue (tissue), primary culture (primary culture), the GFP-positive cell fraction $\left(\mathrm{GFP}^{+}\right)$, and the GFP-negative cell fraction $\left(\mathrm{GFP}^{-}\right)$were analyzed by RT-PCR for mRNA of integrin- $\beta 1,-\alpha 1,-\alpha 2,-\alpha 3,-\alpha 6$, $-\alpha 10$, and $-\alpha 11$ subunits; $G H ;$ S100 $\beta$ protein $(S 100 \beta)$; and GAPDH. (B) Immunohistochemistry for integrin $\beta 1$ subunit in the anterior pituitary gland. Immunoreactivity of the integrin $\beta 1$ subunit (red) was observed in both GFP-positive cells (FS cells, green) and GFP-negative cells. Scale bar, $10 \mu \mathrm{m}$.

\section{Discussion}

In the present study, we observed living FS cells in primary culture of S100b-GFP rat anterior pituitary cells and noted that FS cells markedly extend and contract their cytoplasmic processes by arranging actin filaments in their cytoplasm, thereby interconnecting with neighboring FS cells. FS cells also adhere to small clusters of GFP-negative cells and aggregate into ever-larger clusters during the course of cytoplasmic contraction. In the presence of ECM, FS cells markedly change their shape and exhibit proliferative activity.

By means of living-cell imaging, we confirmed that FS cells are capable of extending their cytoplasmic processes, as shown in Fig. 1A and B. Because actin filaments were detected in FS cells with long cytoplasmic processes, but not in round FS cells (Fig. 4B), we believe that FS cells extend and contract their cytoplasmic processes by rearrangement of their actin cytoskeleton. Toral et al. (2003) reported that in primary culture of anterior pituitary cells, changes in the morphology of hormone-producing cells of infant rats were facilitated by alteration of the arrangement of actin filaments, a process that was not observed in adults. In the present study, hormoneproducing cells in adults remained round, as described in Toral et al. (2003); however, in our study, FS cells in adults behaved in a manner similar to that observed in infants. After the interconnection of cytoplasmic processes, FS cells pull toward each other by contracting these processes (Fig. 1 and Supplementary movies 1 and 2) and small clusters of GFP-negative cells attach to the FS cells, which results in the formation of a larger cluster. We also noted that the number of cells in a cluster was significantly higher in the presence of FS cells (Fig. 2). These findings suggest that this cluster formation in anterior pituitary cells partly depends on the activity of FS cells.

FS cells formed interconnections with neighboring FS cells in primary culture. A similar phenomenon was observed in a culture experiment using TtT/GF cells line, i.e. cloned FS cells (Yamasaki et al. 1997). Interestingly, some FS cells precisely extend their cytoplasmic processes toward other cells, as shown in Fig. 3. This suggests the presence of guidance factors similar to those observed in axon growth cones. Axons respond to certain chemoattractants and chemorepellents, which function as permissive and nonpermissive guidance signals (Nakamura et al. 2000, Round \& Stein 2007). The results of the present experiment indicate that a similar mechanism may be involved in establishing interconnections between FS cells. At the tips of the cytoplasmic processes of TtT/GF cells, annexin I, which is known to be a paracrine factor in the gland, is immunohistochemically localized, and may function as a paracrine guidance substance, as suggested by Chapman et al. (2002).

FS cells in anterior pituitary gland connect to each other not only by mechanical means, but also by gap junctionmediated biochemical communication (Soji \& Herbert 1989). This system of connections is referred to as the FS cell network. In vivo electrophysiological studies have shown that FS cells form networks that transmit stimulation to neighboring FS cells as $\mathrm{Ca}^{2+}$ waves through gap junction channels (Fauquier et al. 2001, Sato et al. 2005). It has also been shown that FS cells in vitro can transfer small molecules to neighboring FS cells through gap junction coupling (Morand et al. 1996, Kabir et al. 2005). In addition, we recently reported that FS cells reconstructed gap junctions in primary culture of S100b-GFP rat anterior pituitary cells (Horiguchi et al. 2008). Indeed, the living-cell image shown in Fig. 3 may show the initiation of FS cell network reconstruction.

In our first attempt to investigate the interaction of FS cells and ECM, we examined whether FS cells respond to ECM components of the basement membrane (collagen type IV, laminin, and fibronectin) and to interstitial collagens (collagen 
types I and III). We observed that FS cells first become flatter and markedly extend their cytoplasmic processes to form numerous interconnections with neighboring FS cells in the presence of ECM (Fig. 5). ECM affects FS cells not only morphologically, but also functionally. On the surface of ECM, FS cells exhibited marked proliferation and GFP-negative cells showed almost no proliferation (Fig. 6 and Supplementary movie 3). This difference in proliferation was confirmed by the BrdU incorporation experiment (Fig. 6E and F). Wilson (1986) examined tritiated thymidine uptake and suggested that, as compared to all types of hormone-producing cells, FS cells may proliferate more frequently in adult anterior pituitary gland in vivo. However, to our knowledge, the present study is the first to directly demonstrate proliferation of FS cells.

We investigated the expressions of possible receptor molecules for the ECM components, i.e. integrin subunits, in FS cells by RT-PCR using GFP-positive cell fractions. We are the first to note that FS cells expressed integrin- $\alpha 1$, $-\alpha 3,-\alpha 6$, and $-\beta 1$ (Fig. $7 \mathrm{~A}$ ); it was previously reported that integrin $\alpha 5$ was expressed in anterior pituitary cells in vivo and in vitro (Horacek et al. 1994, Kikuchi et al. 2005). Integrins comprise an $\alpha$ - and a $\beta$-subunit, which form a heterodimer. In mammals, 18 types of $\alpha$-subunits and 8 types of $\beta$-subunits are known; their various combinations give rise to 24 integrin heterodimers, which differ in ligand specificity (Hynes 2002). With respect to these ligand specificities, we believe that FS cells bind collagen, laminin, and fibronectin through integrin- $\alpha 1 \beta 1,-\alpha 3 \beta 1$, and/or $-\alpha 6 \beta 1$, and integrin $\alpha 5 \beta 1$ respectively in the anterior pituitary gland. Immunohistochemistry confirmed that the common integrin $\beta 1$ subunit was expressed in GFP-positive and GFP-negative cells (Fig. 7B). However, a number of FS cells did not extend cytoplasmic processes and maintained a round shape throughout $72 \mathrm{~h}$ of culture. There are two possible explanations for this difference in morphology. The difference may be due to heterogeneity in FS cells. FS cells are classified into several types based on their content, i.e. keratin, glial fibrillary acidic protein, or major histocompatibility complex class II antigen (Höfler et al. 1984, Tachibana \& Yamashima 1988, Allaerts et al. 1996). The variation in response to ECM may be due to differences between these FS cell types. The morphological difference may also be due to variation in the intracellular signal pathways. In addition to its role as a molecule that facilitates mechanical adhesion to ECM, integrin is known to act as a starting point for various signaling pathways that regulate cell migration and proliferation (Martin et al. 2002). Integrin may associate differently with the intracellular signaling pathways in FS cells that do and do not extend cytoplasmic processes. If so, this would constitute matricrine regulation of FS cells.

Accumulating evidence indicates that FS cells have numerous possible functions. In the postnatal development of the anterior pituitary gland, FS cells are reported to act as stem and proliferative progenitor cells (Yoshimura et al. 1977, Horvath \& Kovacs 2002, Inoue et al. 2002). They also possess phagocytotic activity (Horvath et al. 1974, Ogawa et al. 1997). Furthermore, FS cells regulate hormone-producing cells by secreting paracrine factors such as basic fibroblast growth factor (Ferrara et al. 1987), vascular endothelial growth factor (Gospodarowicz \& Lau 1989), IL-6 (Vankelecom et al. 1989), and nitrogen oxide (Chen et al. 2000). Finally, the present study revealed that FS cells, under the influence of ECM components, may play important functional roles in determining and/or maintaining local cellular arrangement in the anterior pituitary gland.

\section{Supplementary data}

This is linked to the online version of the paper at http://dx.doi.org/10.1677/ JOE-09-0333.

\section{Declaration of interest}

The authors declare that there is no conflict of interest that would prejudice the impartiality of this research.

\section{Funding}

This work was partly supported by a Grant-in-Aid for Scientific Research (C) (19590194) and (21570067) from the Ministry of Education, Culture, Sports, Science, and Technology of Japan.

\section{Acknowledgements}

We thank Prof. K Inoue (Saitama University, Japan) for supplying the transgenic rats. We are grateful to $M$ Yatabe for her excellent technical assistance. We also thank David Kipler, ELS, of Supernatant Communications for revising the language of the manuscript.

\section{References}

Allaerts W, Fluitsma DM, Hoefsmit EC, Jeucken PH, Morreau H, Bosman FT \& Drexhage HA 1996 Immunohistochemical, morphological and ultrastructural resemblance between dendritic cells and folliculo-stellate cells in normal human and rat anterior pituitaries. Journal of Neuroendocrinology 8 17-29.

Chapman L, Nishimura A, Buckingham JC, Morris JF \& Christian HC 2002 Externalization of annexin I from a folliculo-stellate-like cell line. Endocrinology 143 4330-4338.

Chen L, Maruyama D, Sugiyama M, Sakai T, Mogi C, Kato M, Kurotani R, Shirasawa N, Takaki A, Renner U et al. 2000 Cytological characterization of a pituitary folliculo-stellate-like cell line, Tpit/F1, with special reference to adenosine triphosphate-mediated neuronal nitric oxide synthase expression and nitric oxide secretion. Endocrinology 141 3603-3610.

Denduchis B, Rettori V \& McCann SM 1994 Role of laminin on prolactin and gonadotrophin release from anterior pituitaries of male rats. Life Sciences 55 1757-1765.

Diaz ES, Rettori V, Suescun MO, Lustig L, McCann SM \& Denduchis B 2002 Role of type IV collagen in prolactin release from anterior pituitaries of male rats. Endocrine 18 185-189.

Fauquier T, Guérineau NC, McKinney RA, Bauer K \& Mollard P 2001 Folliculostellate cell network: a route for long-distance communication in the anterior pituitary. PNAS 98 8891-8896. 
Ferrara N, Schweigerer L, Neufeld G, Mitchell R \& Gospodarowicz D 1987 Pituitary follicular cells produce basic fibroblast growth factor. PNAS $\mathbf{8 4}$ 5773-5777.

Gon G, Shirasawa N \& Ishikawa H 1987 Appearance of the cyst- or ductulelike structures and their role in the restoration of the rat pituitary autograft. Anatomical Record 217 371-378.

Gospodarowicz D \& Lau K 1989 Pituitary follicular cells secrete both vascular endothelial growth factor and follistatin. Biochemical and Biophysical Research Communications 165 292-298.

Höfler H, Denk H \& Walter GF 1984 Immunohistochemical demonstration of cytokeratins in endocrine cells of the human pituitary gland and in pituitary adenomas. Virchows Archiv. A, Pathological Anatomy and Histopathology 404 359-368.

Horacek MJ, Kawaguchi T \& Terracio L 1994 Adult adenohypophysial cells express beta 1 integrins and prefer laminin during cell-substratum adhesion. In Vitro Cellular \& Developmental Biology. Animal 30 35-40.

Horiguchi K, Fujiwara K, Kouki T, Kikuchi M \& Yashiro T 2008 Immunohistochemistry of connexin 43 throughout anterior pituitary gland in a transgenic rat with green fluorescent protein-expressing folliculo-stellate cells. Anatomical Science International 83 256-260.

Horvath E \& Kovacs K 2002 Folliculo-stellate cells of the human pituitary: a type of adult stem cell? Ultrastructural Pathology 26 219-228.

Horvath E, Kovacs K, Penz G \& Ezrin C 1974 Origin, possible function and fate of 'follicular cells' in the anterior lobe of the human pituitary. American Journal of Pathology 77 199-212.

Hynes RO 2002 Integrins: bidirectional, allosteric signaling machines. Cell 110 673-687.

Inoue K, Couch EF, Takano K \& Ogawa S 1999 The structure and function of folliculo-stellate cells in the anterior pituitary gland. Archives of Histology and Cytology 62 205-218.

Inoue K, Mogi C, Ogawa S, Tomida M \& Miyai S 2002 Are folliculo-stellate cells in the anterior pituitary gland supportive cells or organ-specific stem cells? Archives of Physiology and Biochemistry 110 50-53.

Itakura E, Odaira K, Yokoyama K, Osuna M, Hara T \& Inoue K 2007 Generation of transgenic rats expressing green fluorescent protein in S-100beta-producing pituitary folliculo-stellate cells and brain astrocytes. Endocrinology 148 1518-1523.

John CD, Christian HC, Morris JF, Flower RJ, Solito E \& Buckingham JC 2004 Annexin 1 and the regulation of endocrine function. Trends in Endocrinology and Metabolism 15 103-109.

Kabir N, Chaturvedi K, Liu LS \& Sarkar DK 2005 Transforming growth factor-beta 3 increases gap-junctional communication among folliculostellate cells to release basic fibroblast growth factor. Endocrinology 146 4054-4060.

Kikuchi M, Sunaga K, Yatabe M, Takigami S, Sakamoto A \& Yashiro T 2005 An in vivo and in vitro immunohistochemical study of integrin alpha subunit localization in the rat anterior pituitary. Acta Histochemica et Cytochemica 38 381-386.

Martin KH, Slack JK, Boerner SA, Martin CC \& Parsons JT 2002 Integrin connections map: to infinity and beyond. Science 296 1652-1653.

Morand I, Fonlupt P, Guerrier A, Trouillas J, Calle A, Remy C, Rousset B \& Munari-Silem Y 1996 Cell-to-cell communication in the anterior pituitary: evidence for gap junction-mediated exchanges between endocrine cells and folliculostellate cells. Endocrinology 137 3356-3367.

Nakamura F, Kalb RG \& Strittmatter SM 2000 Molecular basis of semaphorin-mediated axon guidance. Journal of Neurobiology 44 219-229.

Noda T, Kaidzu S, Kikuchi M \& Yashiro T 2001 Topographic affinities of hormone-producing cells in the rat anterior pituitary gland. Acta Histochemica et Cytochemica 34 313-319.
Ogawa S, Ishibashi Y, Sakamoto Y, Kitamura K, Kubo M, Sakai T \& Inoue K 1997 The glycoproteins that occur in the colloid of senescent porcine pituitary glands are clusterin and glycosylated albumin fragments. Biochemical and Biophysical Research Communications 234 712-718.

Otis M, Campbell S, Payet MD \& Gallo-Payet N 2007 Expression of extracellular matrix proteins and integrins in rat adrenal gland: importance for ACTH-associated functions. Journal of Endocrinology 193 331-347.

Paez-Pereda M, Kuchenbauer F, Arzt E \& Stalla GK 2005 Regulation of pituitary hormones and cell proliferation by components of the extracellular matrix. Brazilian Journal of Medical and Biological Research 38 1487-1494.

Rinehart JF \& Farquhar MG 1953 Electron microscopic studies of the anterior pituitary gland. Journal of Histochemistry and Cytochemistry 193-113.

Round J \& Stein E 2007 Netrin signaling leading to directed growth cone steering. Current Opinion in Neurobiology 17 15-21.

Sato Y, Hashitani H, Shirasawa N, Sakuma E, Naito A, Suzuki H, Asai Y, Sato G, Wada I, Herbert DC et al. 2005 Intercellular communications within the rat anterior pituitary XII: immunohistochemical and physiological evidences for the gap junctional coupling of the folliculo-stellate cells in the rat anterior pituitary. Tissue \& Cell 37 281-291.

Shirasawa N, Mabuchi Y, Sakuma E, Horiuchi O, Yashiro T, Kikuchi M, Hashimoto Y, Tsuruo Y, Herbert DC \& Soji T 2004 Intercellular communication within the rat anterior pituitary gland: X. Immunohistocytochemistry of S-100 and connexin 43 of folliculo-stellate cells in the rat anterior pituitary gland. Anatomical Record. Part A 278 462-473.

Soji T \& Herbert DC 1989 Intercellular communication between rat anterior pituitary cells. Anatomical Record 224 523-533.

Tachibana O \& Yamashima T 1988 Immunohistochemical study of folliculo-stellate cells in human pituitary adenomas. Acta Neuropathologica 76 458-464.

Toral C, Solano-Agama MC, Luna J, Romano MC \& Mendoza-Garrido ME 2003 Epidermal growth factor induces an increase in cell adhesion and an arrangement of actin skeleton in stress fibres in pituitary cultured cells from infantile rats but not adult rats. Journal of Cellular Physiology 195 80-91.

Vankelecom H \& Denef C 1997 Paracrine communication in the anterior pituitary as studied in reaggregate cell cultures. Microscopy Research and Technique 15 150-156.

Vankelecom H, Carmeliet P, Van Damme J, Billiau A \& Denef C 1989 Production of interleukin-6 by folliculo-stellate cells of the anterior pituitary gland in a histiotypic cell aggregate culture system. Neuroendocrinology 49 102-106.

Wilson DB 1986 Distribution of ${ }^{3} \mathrm{H}$-thymidine in the postnatal hypophysis of the C57BL mouse. Acta Anatomica 126 121-126.

Yamasaki T, Fujita H, Inoue K, Fujita T \& Yamashita N 1997 Regulation of $\mathrm{K}+$ channels by cell contact in a cloned folliculo-stellate cell (TtT/GF). Endocrinology 138 4346-4350.

Yashpal NK, Li J, Wheeler MB \& Wang R 2005 Expression of $\beta 1$ Integrin receptors during rat pancreas development-sites and dynamics. Endocrinology 146 1798-1807.

Yoshimura F, Soji T, Sato S \& Yokoyama M 1977 Development and differentiation of rat pituitary follicular cells under normal and some experimental conditions with special reference to an interpretation of renewal cell system. Endocrinologia Japonica 24 435-449.

Received in final form 14 October 2009

Accepted 9 November 2009

Made available online as an Accepted Preprint

9 November 2009 